\title{
A case of primary gastric diffuse large B-cell lymphoma occurring in chronic myeloid leukemia
}

This article was published in the following Dove Press journal:

OncoTargets and Therapy

Zhimei Cai ${ }^{1,2}$
Shuo Liu'
Jie Zi'
Jinlong Ma'
Zheng Ge ID'
'Department of Hematology, Zhongda
Hospital Southeast University, Institute of
Hematology Southeast University,
Nanjing 210009 , Jiangsu, People's
Republic of China; '2Department of
Hematology, Affiliated Lianyungang
Hospital of Xuzhou Medical University,
Lianyungang 222002, Jiangsu, People's
Republic of China

Republic of China
Correspondence: Zheng Ge

Department of Hematology, Zhongda Hospital Southeast University, Institute of Hematology Southeast University, No. 87 Dingjiaqiao, Gulou District, Nanjing

210009, Jiangsu Province, People's

Republic of China

Tel +862583262468

Fax +86 258326247

Email Janege879@hotmail.com

\begin{abstract}
Chronic myeloid leukemia (CML) and Non-Hodgkin Lymphoma (NHL) are two different origins of hematological malignancies, which rarely occur at the same time. Moreover, NHL secondary to CML is common in T cell lymphoma, while NHL of B cell origin is rare. Since 1999, only 22 cases with B cell lymphoma have been reported, of which 4 cases have diffuse large B-cell lymphoma (DLBCL). The lesions of DLBCL were in lymph node, liver, jejunum, and soft palate. To our knowledge, it has no report for the primary gastric DLBCL (PG-DLBCL) occurring in CML. Here we reported a 63-year-old man of chronic phase (CP) CML associated with PG-DLBCL. The patient was diagnosed with CML nearly eight years ago and was treated with imatinib and nilotinib successively. However, gastroscopy found malignant lesions in the patient's stomach in March 2018, and the masses were diagnosed as PG-DLBCL. Subsequently, with the treatment of the RCOP + lenalidomide regimen chemotherapy for 3 cycles, the patient achieved nearly complete remission (CR).
\end{abstract}

Keywords: primary gastric diffuse large B-cell lymphoma, chronic myeloid leukemia, simultaneous

\section{Introduction}

Chronic myelogenous leukemia (CML) is a common malignant tumor in the hematopoietic system. The incidence of CML is about $10-12 / 100,000^{1}$ every year in the world. With the increase of age, the incidence of CML tends to increase gradually. CML is characterized by the presence of the Philadelphia chromosome $(\mathrm{Ph})(\mathrm{t}(9 ; 22)(\mathrm{q} 34 ; \mathrm{q} 11.2))$ and the fusion gene of breakpoint cluster/Abelson tyrosine kinase $(B C R / A B L),{ }^{2}$ and it is divided into three stages according to its clinical characteristics: chronic phase (CP), accelerated phase (AP) and blast crisis (BC). ${ }^{2}$ The treatment for CML used to be only relied on chemotherapy (hydroxyurea, busulfan, etc.) or interferon-alfa (IFN- $\alpha$ ) to control their condition for a long time, although the efficacy of this treatment scheme is not ideal. Recently the allogeneic stem cell transplantation (allo-SCT) showed curative to CML, but only a few patients can benefit from allo-SCT because of the limitation of donor source, age, and so on. ${ }^{3}$ Since the first generation tyrosine kinase inhibitor (TKI) imatinib mesylate (IM) is approved by the FDA (Food and Drug Administration) as the first-line treatment of CML- CP in 2001, it has been used for more than 10 years. TKI treatment results in great improvement of the prognosis of CML-CP patients, particularly the long-term use of TKI has obtained signfiicant results, eight years Overall Survival (OS) was close to $92 \% .{ }^{4}$ However, the continued use of these drugs may increase the risk of secondary malignancies. ${ }^{5}$ It is reported that CML patients are prone to complicate with acute leukemia or lymphoma due to chromosome changes. ${ }^{6}$ In addition, some experts 
have demonstrated that simultaneous $\mathrm{T}$ cell lymphoma and myeloid leukemia is more than simultaneous B cell lymphoma and myeloid. ${ }^{7,8}$ Primary gastric lymphoma (PGL) is an uncommon tumor, accounting for approximately $10 \%$ of gastric malignant tumors and about $5 \%$ of all lymphomas. ${ }^{9,10}$ However, PGL is the second most common malignant tumors in gastric cancer. ${ }^{9}$ Furthermore, PGL is one of the most common extranodal lymphomas, which accounts for 30$50 \%$ of primary extranodal lymphomas. ${ }^{10}$ The most common pathological type of PGL is primary gastric diffuse large Bcell lymphoma (PG-DLBCL), followed by mucosa-associated lymphoid tissue(MALT). ${ }^{11}$ Most PG-DLBCL originate from $\mathrm{B}$ cells and very few from $\mathrm{T}$ cells.

\section{Case report}

A 63-year-old man was diagnosed as CML-CP due to elevated white blood cells (WBC) counts at the Air Force 454 Hospital (Nanjing, Jiangsu, China) and treated with imatinib in June 2011. Three months later, the patient switched the second-generation TKI (nilotinib) because he could not tolerate the adverse effects of imatinib- rash and itchy skin. The patient presented to Gaochun County Hospital (Gaochun, Jiangsu, China) on March $8^{\text {th }}, 2018$ for a sudden weakness of the left limb without speech loss, vomiting, fever, weight loss or night sweats. The magnetic resonance imaging (MRI) of the brain revealed an acute cerebral infarction in the right temporal lobe. The patient's condition gradually stabilized after active symptomatic treatment. A gastroscopic biopsy was performed because of the patient's complaint of the gastric discomfort for several months and then it was diagnosed as small cell gastric cancer. During hospitalization in Gaochun County Hospital, the patient appeared the left limb weakness again, and he was transferred to the department of internal medicine and neurology of our hospital on March $15^{\text {th }}$, 2018. The MRI scan of the brain showed acute cerebral infarction of right cerebral hemisphere, multiple sulcus in the brain. Continued with the symptomatic treatment, the patient's gastric biopsy tissue was re-examined by the pathology department of our hospital, and it was primarily diagnosed as a non-germinal center DLBCL (non-GCB). Immunohistochemistry showed: CD34 (+), CD10 (-), Mum-1 (a few cells were positive), BCL-6 (approximately 80\%+), BCL-2 (-), C-MYC (approximately 80\%+), CD5 (-), CD30 (-), P53 (several cells were positive), LCA (+), CD3 (-), CD7 (-), CD20 (+), EBER (-), Ki67 (approximately $80 \%+)$, CD3 (-), CD20 ( \pm ), CD79a ( \pm ), PAX5 (+), CD45RO (-), LCA (+), panCK (-). Fluorescence in situ hybridization (FISH) did not detect IGH/BCL2 gene fusion (Figure 1A), BCL6 (Figure 1B), and C-MYC (Figure 1C) gene fragmentation or recombination. HP infections history was not available in the patient. After the patient's symptoms of acute cerebral infarction were controlled, he was transferred to our Hematology department on April 2 ${ }^{\text {nd }}, 2018$.

Physical examination revealed no enlarged superficial lymph nodes, splenomegaly or hepatomegaly. Laboratory tests showed: WBC count: $4.09 \times 10^{9} / \mathrm{L}$, red blood cell (RBC) count: $2.74 \times 10^{12} / \mathrm{L}$, hemoglobin (Hb): $90 \mathrm{~g} / \mathrm{L}$, platelet (PLT) count: $124 \times 10^{9} / \mathrm{L} ; \beta 2$ Microglobulin ( $\beta 2-\mathrm{MG}): 2.07 \mathrm{mg} / \mathrm{L}$; Lactic Dehydrogenase (LDH): 236 IU/L. Bone marrow smear showed that the positive rate of neutrophil alkaline phosphatase (NAP) staining was 54\% and the score was 66 points but did not find primordial cells. The BCR/ABL fusion gene was identified in the bone marrow cells by FISH, which revealed the presence of the transcript for $\mathrm{BCR} / \mathrm{ABL} \mathrm{P} 210$ (positive rate, $11.63 \%$ ). Positron emission tomography (PET) (Figure 2A) was performed and showed no evidence of lymphoma infiltration except for malignant lesions at the bottom of the stomach. There was no abnormal change in liquid biopsy and ABL kinase mutation.

In conclusion, the patient can be diagnosed as CML$\mathrm{CP}$ (complete hematological remission, CHR) with PG-
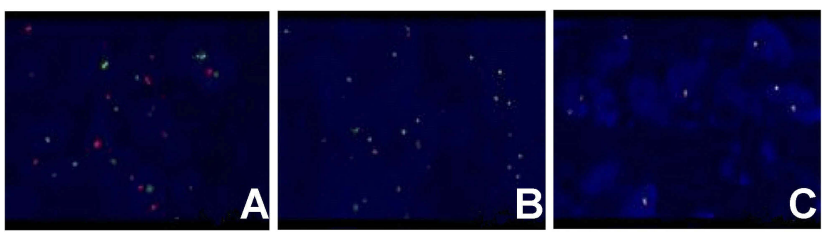

Figure I FISH results: FISH (Gastric Biopsy) did not detect IGH/BCL2 (A) gene fusion, BCL6 (B) and C-MYC (C) gene fragmentation or recombination.
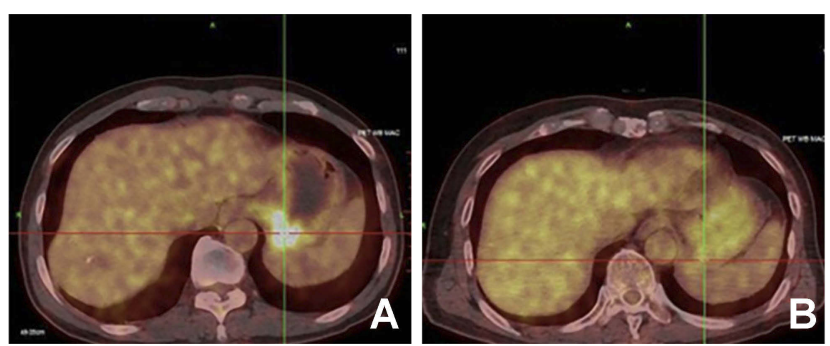

Figure 2 PET data: (A) PET on 2018/3/2I: Abnormal increase of FDG metabolism in the irregular thickening of the gastric wall on the small curvature side of the stomach bottom malignant; (B) PET on 2018/8/14: The metabolism of FDG in gastric fundus was slightly elevated, and no specific active tumors were found. 
DLBCL (Ann Arbor staging system:IIEA, IPI score:4, Lugano staging system:I) and acute cerebral infarction. The patient was an elderly male with acute cerebral infarction, long-term bed rest, poor appetite, and low immune function, also the pathological type of DLBCL in the patient belonged to non-germinal center subtype; in order to prevent the increase of cardiac and bone marrow toxicity of anthracycline - doxorubicin, he was treated with RCOP and Lenalidomide (rituximab $375 \mathrm{mg} / \mathrm{m}^{2} \mathrm{~d} 0$, cyclophosphamide $750 \mathrm{mg} / \mathrm{m}^{2} \mathrm{~d} 1$, vindesine $2.5 \mathrm{mg} / \mathrm{m}^{2} \mathrm{~d} 1$, dexamethasone $0.75 \mathrm{mg} / \mathrm{m}^{2} \mathrm{~d} 1-5$, lenalidomide $10 \mathrm{mg}$ d1-21) regimen chemotherapy every 28 days from April 2018 to July 2018. Considering that chronic and poor general condition and the unstable blood cell count before chemotherapy, and also reducing the risk of bone marrow suppression resulted from the combination therapy, nilotinib was continuously administered with a dose of $400 \mathrm{mg}$ once daily.

Three cycles later, PET (Figure 2B) showed that there was no clear active tumor tissue in the whole body, which suggested that the patient achieved nearly complete remission (CR) from PG-DLBCL. However, the presence of $\mathrm{BCR} / \mathrm{ABL} \mathrm{P} 210$ transcripts with a positive rate of $61 \%$ was detected by FISH in bone marrow cells. In order to achieve a better therapeutic efficacy on CML, the dose of nilotinib was subsequently increased to $400 \mathrm{mg}$ twice daily. The chemotherapy regimen was adjusted to RP (rituximab $375 \mathrm{mg} / \mathrm{m}^{2} \mathrm{~d} 0$, dexamethasone $0.75 \mathrm{mg} / \mathrm{m}^{2}$ d1-5) for three courses due to the low blood cell counting of the patient during the past three cycles of chemotherapy, and the patients' blood routine gradually returned to normal, and the patient restored the RCOP regimen chemotherapy in December 2018. In the scheme, dexamethasone is selected in place of prednisolone owing to the patient had poor appetite and stomach discomfort, which would avoid the additional gastrointestinal burden associated with large doses of prednisone. Unfortunately, although the condition improved after the active treatment, the patient refused the ongoing therapy for the fear of chemotherapy.

\section{Discussion}

CML and Non-Hodgkin lymphoma (NHL) belong to malignant tumors with different origins. NHL is rare in CML; the majorities are $\mathrm{T}$ cell lymphomas with an immature thymic phenotype, while B cell lymphomas are much rare. ${ }^{7,12}$ With literature search, we found only twenty-two cases of B cell lymphomas occurring in patients with CML in the
PUBMED since 1999 (Table 1). The patients included fourteen males and nine females. All were adults with a median age of 63 years. These lymphomas included the following types, five diffuse large B-cell lymphoma (including our case), ${ }^{7,13-15}$ five chronic lymphocytic Leukemia/small lymphocytic lymphoma (CLL/SLL), ${ }^{16-20}$ three plasma cell neoplasm (PCN), ${ }^{21-23}$ two follicular lymphoma (FL), ${ }^{24,25}$ two Mantle Cell Lymphoma (MCL), ${ }^{26,27}$ two Mediastinal B cell lymphoma (MBCL), ${ }^{28,29}$ one large-cell NHL, ${ }^{30}$ one B-cell lymphoma, $^{12}$ one mucosa-associated lymphoid tissue (MALT) lymphoma, ${ }^{31}$ one extranodal marginal zone Bcell lymphoma (EMZBCL). ${ }^{32}$ As shown in Table 1, there are 4 cases of DCBCL with CML have been published, however, the PG-DLBCL with CML is the first report.

Based on the patient's clinical symptoms, PET, gastric biopsy tissue and immunohistochemistry, the lymphoma in this patient was rated as Ann Arbor staging system (IIEA), Lugano $^{33,34}$ staging system (I), IPI ${ }^{35}$ score (4). The former two staging methods suggested that the prognosis of patients was better, ${ }^{36}$ but his age and inability to take care of himself, poor pathological type and high Ki-67 expression, all of those increase the difficulty of treatment. The patient showed the positive expression of CD20 and the pathological type of non-germinal center subtype, therefore RCOP combined with lenalidomide regimen was used. After three cycles of the treatment, PET showed that the gastric mass disappeared and the curative effect reached the basic $\mathrm{CR}$. However, the FISH test indicates that $\mathrm{BCR} / \mathrm{ABL}$ is higher than before, indicating the chemotherapy sheme is not ideal for CML; after increasing the dose of nilotinib and reducing the chemotherapeutic regimen, the patient condition was stable. This suggested it also needs to minitor the progress of CML and pay attention to CML treatment while treatment of lymphoma. Our chemothrepay scheme alteration showed a stable efficacy for the patient, which may give some hints for the treatment of this type of patients.

PGL is an uncommon type of gastrointestinal tumor; and the most common pathological type of PGL is PGDLBCL, ${ }^{11}$ which is mostly primary and can also be transformed from other types such as MALT and small B-cell lymphoma. Aleman B M P reported that PG-DLBCL was mostly seen in middle-aged and elderly men, mainly in the early stage, and the pathological subtypes were mostly non-GCB. This present case is consistent with the above characteristics. $^{37}$ PG-DLBCL represents a heterogeneous subset of NHL that demonstrates many molecular alterations and somatic mutations. The efficacy of PG-DLBCL 


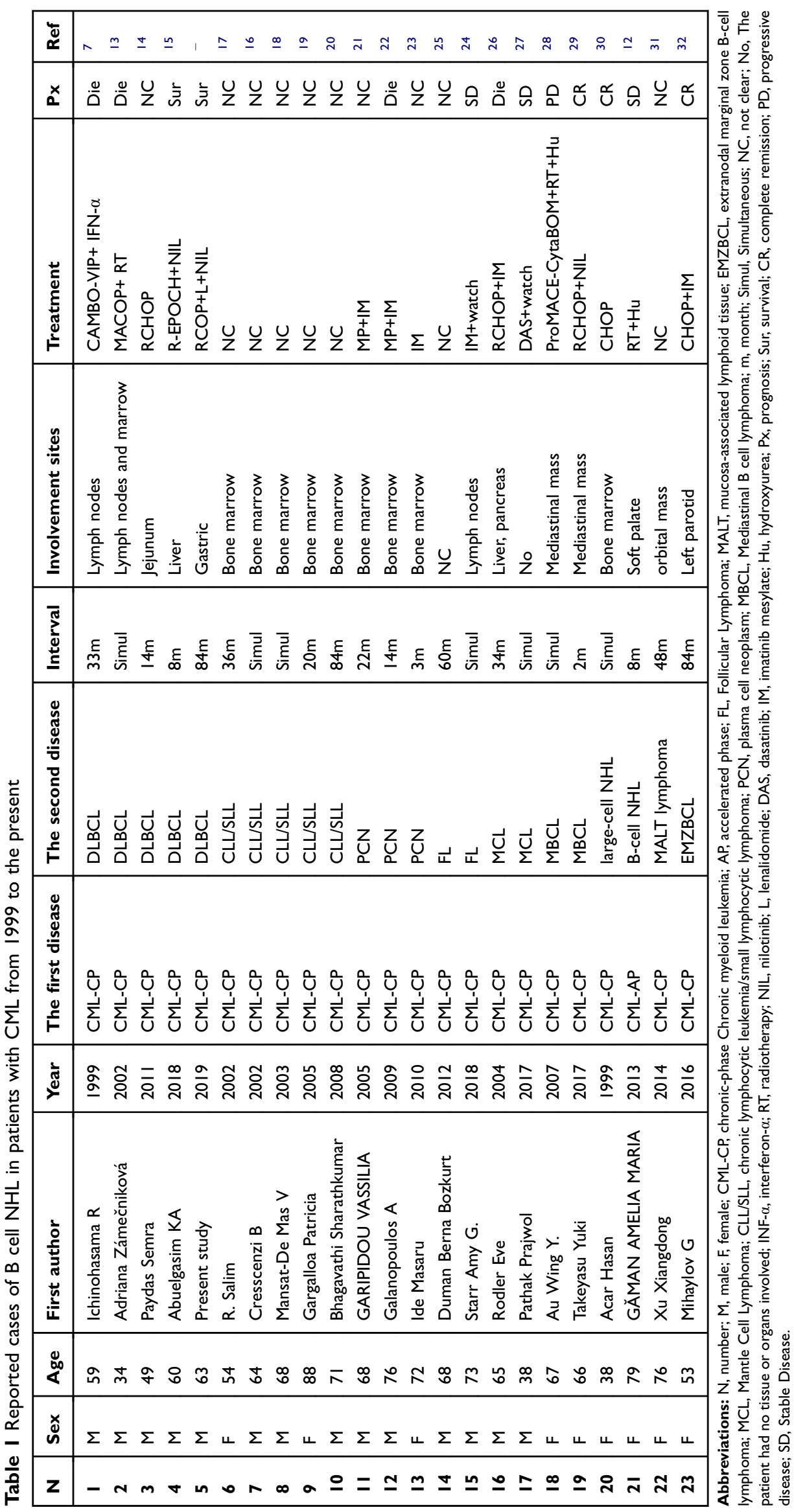


treatment remains controversial. Surgery had been used as a first-line treatment for PG-DLBCL. However, studies have shown that radical gastrectomy for PG-DLBCL is controversial and considered unnecessary, which is recommended as an emergency treatment for severe perforation or bleeding. ${ }^{38}$ Studies have shown that rituximab can significantly improve the prognosis of DLBCL. ${ }^{39}$ Among the five patients with CML and DLBCL, three patients survived well until the publication of the journal after using the combination therapy of rituximab (RCHOP, R$\mathrm{EPOCH}$, and $\mathrm{RCOP}+$ lenalidomide, respectively), while the other two had poor outcomes and died of complications. This report supports the rituximab effect on this type of patients although some reports argued that rituximab did not improve the survival rate of extranodal DLBCL patients. ${ }^{40}$ Lenalidomide has been widely used as an immunomodulatory drug in multiple myeloma and myelodysplastic syndrome, it is also reported that it can also be used in DLBCL patients in recent years, especially in nonGCB patients with poor prognosis, which can improve their prognosis. ${ }^{41-43}$ Lenalidomide has promoting immunity effect by stimulating natural killer cells to enhance the natural immune system to increase its antitumor activity and inhibit angiogenesis. ${ }^{44}$ Our data showed that a combined treatment regimen of RCOP and lenalidomide achieved the $\mathrm{CR}$ for the patient, indicating this regimen is an effective therapy for treatment of primary gastric DLBCL (PG-DLBCL) with CML. Our data also support the above viewpoint that rituximab and lenalidomide have therapeutic effect on DLBCL.

TKI has been used as the first-line treatment for CML for more than ten years, and its effect is remarkable. However, long-term use of TKI may lead to the risk of secondary malignancies. It has been shown that imatinib inhibits the effector function of T-lymphocytes and injures the differentiation of peripheral blood progenitor cells into dendritic cells. ${ }^{45}$ However, some scholars reported that long-term use of TKI did not increase the risk of carcinogenesis compared with the general population. ${ }^{46}$ Furthermore, analysis of patient data from multiple phase I and II trials at the MD Anderson Cancer Center, who were treated with TKI for CML, revealed a risk of secondary malignancies that was lower than expected in the healthy population. ${ }^{47}$ Even so, the chromosome mutation in CML patients suggests that the unstable function of stem progenitor cells is still a high risk factor for carcinogenesis. ${ }^{6}$ Therefore, we still need to be vigilant and strengthen regular follow-up in the process of diagnosis and treatment of CML patients.
In 2015, Bohers et al first validated that liquid biopsy could be used to assist diagnosis and prognosis judgment during the examination of DLBCL patient. ${ }^{48}$ Although no positive results were found in the reported patient, more attention should be paid to liquid biopsy in the diagnosis of lymphoma in the future. As a non-invasive diagnostic method, liquid biopsy has unique advantages in early and precise diagnosis and prognosis, evaluation. Tissue biopsy is limited by the location of biopsy, while liquid biopsy may find gene expression that cannot be found by tissue biopsy, which is very helpful to monitor the patient's condition. $^{49-51}$ A liquid biopsy will be widely used in the furture to better monitor minimal residual disease (MRD), by which lymphoma could be completely eradicate. ${ }^{52,53}$

\section{Conclusion}

The patient with simultaneous occurrence of CML and PGDLBCL is a very rare case, and this is first reported for the primary gastric DLBCL (PG-DLBCL). Combination of Rituximab and lenalidomide is an effective therapy for the patients with this type of disease. The effect of this treatment on survival need to be further investigated in a big cohort in the future. Although there is no clear pathogenic link between CML and PG-DLBCL, we still recommend that disease surveillance should be strengthened during TKI treatment.

\section{Acknowledgments}

We thank Huihui Song for their assistance in data collection. This work is supported in part by the National Natural Science Foundation of China (81770172, 81270613); Key Research \& Technology Projects in Jiangsu Province (BE2017747); Milstein Medical Asian American Partnership (MMAAP) Foundation Research Project Award in Hematology (2017); The Health and Family Planning Technology Project in Lianyungang, Jiangsu Province (Grant No. 201711). The patient has provided written informed consent for the publication of case details and accompanying images. This case report does not require institutional approval to publish the case details.

\section{Disclosure}

The authors report no conflicts of interest in this work.

\section{References}

1. Höglund M, Sandin F, Simonsson B. Epidemiology of chronic myeloid leukaemia: an update. Ann Hematol. 2015;94(Suppl 2):S241-247. doi: $10.1007 / \mathrm{s} 00277-015-2314-2$ 
2. Jabbour E, Kantarjian H. Chronic myeloid leukemia: 2018 update on diagnosis, therapy and monitoring. Am J Hematol. 2018;93(3):442459. doi:10.1002/ajh.25011

3. Saglio G, Kim DW, Issaragrisil S, et al. Nilotinib versus imatinib for newly diagnosed chronic myeloid leukemia. $N$ Engl J Med. 2010;362 (24):2251-2259. doi:10.1056/NEJMoa0912614

4. Rüdiger H, Müller MC, Michael L, et al. Deep molecular response is reached by the majority of patients treated with imatinib, predicts survival, and is achieved more quickly by optimized high-dose imatinib: results from the randomized CML-study IV. J Clin Oncol. 2014;32(5):415-423. doi:10.1200/JCO.2013.49.9020

5. Miranda MB, Lauseker M, Kraus MP, et al. Secondary malignancies in chronic myeloid leukemia patients after imatinib-based treatment: long-term observation in CML study IV. Leukemia. 2016;30 (6):1255-1262. doi:10.1038/leu.2016.20

6. Fabarius A, Kalmanti L, Dietz CT, et al. Impact of unbalanced minor route versus major route karyotypes at diagnosis on prognosis of CML. Ann Hematol. 2015;94(12):2015-2024. doi:10.1007/s00277015-2494-9

7. Ichinohasama R, Miura I, Takahashi N, et al. Ph-negative nonHodgkin's lymphoma occurring in chronic phase of Ph-positive chronic myelogenous leukemia is defined as a genetically different neoplasm from extramedullary localized blast crisis: report of two cases and review of the literature. Leukemia. 2000;14(1):169-182.

8. Fu X, Shang Y, Zhang L, et al. Analyses and treatment of simultaneous bi-lineage malignancies of myeloid leukemia and lymphoma: two case reports and a literature review. Oncol Lett. 2018;16 (5):6624-6632. doi:10.3892/ol.2018.9447

9. Pier Francesco F, Emanuele Z. Primary gastric lymphoma pathogenesis and treatment: what has changed over the past 10 years? $\mathrm{Br} J$ Haematol. 2010;136(4):521-538.

10. Bautistaquach MA, Ake CD, Chen M, Wang J. Gastrointestinal lymphomas: morphology, immunophenotype and molecular features. J Gastrointest Oncol. 2012;3(3):209-225. doi:10.3978/j.issn.20786891.2012.024

11. Ferrucci PF, Zucca E. Primary gastric lymphoma pathogenesis and treatment: what has changed over the past 10 years? Br J Haematol. 2007;136(4):521-538. doi:10.1111/j.1365-2141.2006.06444.x

12. Gaman AM, Dobrea C, Rotaru I. A case of non-Hodgkin lymphoma in a patient with chronic myeloid leukemia. Rom J Morphol Embryol. 2013;54(4):1141-1145.

13. Adriana Z, Andrej V, Peter HJL. Lymphoma. Coexistence of philadelphia-positive chronic granulocytic leukemia and diffuse large Bcell lymphoma at initial diagnosis. Leuk Lymphoma. 2002;43(2):429431. doi:10.1080/10428190290006288

14. Paydaş S, Bozkurt Duman B, Ergin M. Non-Hodgkin's lymphoma in a chronic myelocytic leukemia patient treated with imatinib. Turk $J$ Haematol. 2011;28(03):232-234. doi:10.5152/tjh.2011.60

15. Abuelgasim KA, Rehan H, Alsubaie M, et al. Coexistence of chronic myeloid leukemia and diffuse large B-cell lymphoma with antecedent chronic lymphocytic leukemia: a case report and review of the literature. J Med Case Rep. 2018;12(1):64. doi:10.1186/s13256-018$1612-4$

16. Crescenzi B, Sacchi S, Marasca R, et al. Distinct genomic events in the myeloid and lymphoid lineages in simultaneous presentation of chronic myeloid leukemia and B-chronic lymphocytic leukemia. Leukemia. 2002;16(5):955-956. doi:10.1038/sj.leu.2402490

17. Salim R, Wang L, Lin K, Clark RE. Chronic lymphocytic leukaemia developing in the course of chronic myeloid leukaemia. Leuk Lymphoma. 2002;43(11):2225-2227. doi:10.1080/1042819021000016140a

18. Mansat-De Mas V, Rigal-Huguet F, Cassar G, Kuhlein E, Laurent G, Dastugue N. Chronic myeloid leukemia associated with B-cell chronic lymphocytic leukemia: evidence of two separate clones as shown by combined cell-sorting and fluorescence in situ hybridisation. Leuk Lymphoma. 2003;44(5):867-869. doi:10.1080/ 1042819031000063435
19. Gargallo P, Cacchione R, Chena C, et al. Chronic lymphocytic leukemia developing in a patient with chronic myeloid leukemia: evidence of distinct lineage-associated genomic events. Cancer Genet Cytogenet. 2005;161(1):74-77. doi:10.1016/j.cancergencyto.2005.01.008

20. Bhagavathi S, Borromeo V, Desai H, Crisan D. Case report and literature review: a rare patient with chronic myeloid leukemia and chronic lymphocytic leukemia. Ann Clin Lab Sci. 2008;38(4):405-409.

21. Garipidou V, Vakalopoulou S, Tziomalos K. Development of multiple myeloma in a patient with chronic myeloid leukemia after treatment with imatinib mesylate. Oncologist. 2005;10(6):457-458. doi:10.1634/theoncologist.10-6-457

22. Galanopoulos A, Papadhimitriou SI, Kritikou-Griva E, Georgiakaki M, Anagnostopoulos NI. Multiple myeloma developing after imatinib mesylate therapy for chronic myeloid leukemia. Ann Hematol. 2009;88(3):281-282. doi:10.1007/s00277-008-0597-2

23. Ide M, Kuwahara N, Matsuishi E, Kimura S, Gondo H. Uncommon case of chronic myeloid leukemia with multiple myeloma. Int $J$ Hematol. 2010;91(4):699-704. doi:10.1007/s12185-010-0546-4

24. Duman BB, Paydas S, Disel U, Besen A, Gurkan E. Secondary malignancy after imatinib therapy: eight cases and review of the literature. Leuk Lymphoma. 2012;53(9):1706-1708. doi:10.3109/ 10428194.2012.666545

25. Starr AG, Jonna SR, Chahine JJ, Kallakury BV, Ujjani CS. Concurrent diagnosis of chronic myeloid leukemia and follicular lymphoma: an unreported presentation. Case Rep Hematol. 2018;2018:7493601. doi:10.1155/2018/7493601

26. Rodler E, Welborn J, Hatcher S, et al. Blastic mantle cell lymphoma developing concurrently in a patient with chronic myelogenous leukemia and a review of the literature. Am J Hematol. 2004;75(4):231238. doi:10.1002/ajh.20025

27. Pathak P, Li Y, Gray BA, May WS Jr, Markham MJ. Synchronous occurrence of chronic myeloid leukemia and mantle cell lymphoma. Case Rep Hematol. 2017;2017:7815095. doi:10.1155/ 2017/7815095

28. Au WY, Ma SK, Wan TS, Wang EP, Lau TC, Kwong YL. Concurrent mediastinal B cell lymphoma and chronic myeloid leukemia with an unusually favorable response to chemotherapy. Leuk Lymphoma. 2003;44(3):535-538. doi:10.1080/1042819021000038029

29. Takeyasu Y, Satake A, Azuma Y, et al. Tyrosine kinase inhibitor and rituximab-CHOP treatment for concurrent chronic myeloid leukemia and non-Hodgkin lymphoma: a case report. Clin Case Rep. 2017;5 (12):2047-2050. doi:10.1002/ccr3.1253

30. Acar H, Ecirli S, Gundogan F, Bulay O, Acar A. Simultaneous occurrence of chronic myelogenous leukemia and non-Hodgkin lymphoma at diagnosis. Cancer Genet Cytogenet. 1999;108 (2): 171-174.

31. Xu X, Hassan A. Extranodal marginal zone lymphoma arising in a patient with chronic myelogenous leukemia on long-term tyrosine kinase inhibitors. Leuk Lymphoma. 2014;55(3):715-717. doi:10.3109/10428194.2013.811581

32. Mihaylov G, Varbanova V, Stoeva V, Dikov T. Extranodal marginal zone B-cell lymphoma arising in chronic myeloid leukaemia successfully treated with tyrosine kinase inhibitor: a case report. Hippokratia. 2016;20(3):241-243.

33. Rohatiner A, D'Amore F, Coiffier B, et al. Report on a workshop convened to discuss the pathological and staging classifications of gastrointestinal tract lymphoma. Ann Oncol. 1994;5(5):397-400. doi:10.1093/oxfordjournals.annonc.a058869

34. Cheson BD, Fisher RI, Barrington SF, et al. Recommendations for initial evaluation, staging, and response assessment of Hodgkin and non-Hodgkin lymphoma: the lugano classification. $J$ Clin Oncol. 2014;32(27):3059-3068. doi:10.1200/JCO.2013.54.8800

35. Vaidya R, Witzig TE. \%J annals of oncology official journal of the european society for medical oncology. Prognostic factors for diffuse large B-cell lymphoma in the R(X)CHOP era. Ann Oncol. 2014;25 (11):2124-2133. doi:10.1093/annonc/mdu109 
36. Miller TP, Dahlberg S, Cassady JR, et al. Chemotherapy alone compared with chemotherapy plus radiotherapy for localized intermediate- and high-grade non-Hodgkin's lymphoma. $N$ Engl J Med. 1998;339(1):21-26. doi:10.1056/NEJM199807023390104

37. Aleman BM, HRDMJBP R, Gastroenterology RC. Role of radiotherapy in the treatment of lymphomas of the gastrointestinal tract Best Pract Res Clin Gastroenterol. 2010;24(1):27-34. doi:10.1016/j. bpg.2009.12.002

38. Ostfeld I, Feins RH, Rouvio O, Dorfman L, Moran-Gilad JJD, Medicine M. Primary gastric lymphoma in a soldier presenting as acute gastrointestinal bleeding. Disaster Mil Med. 2015;1(1):1-4. doi:10.1186/2054-314X-1-1

39. Coiffier B, Thieblemont C, Van Den Neste E, et al. Long-term outcome of patients in the LNH-98.5 trial, the first randomized study comparing rituximab-CHOP to standard CHOP chemotherapy in DLBCL patients: a study by the groupe d'Etudes des lymphomes de l'Adulte. Blood. 2010;116(12):2040-2045. doi:10.1182/blood-2010-03-276246

40. GutiÃ@rrez-GarcÃ-a G, Colomo L, Villamor N, et al. Clinico-biological characterization and outcome of primary nodal and extranodal diffuse large B-cell lymphoma in the rituximab era. Leuk Lymphoma. 2010;51(7):1225-1232. doi:10.3109/10428194.2010.483301

41. Dawson IM, Cornes JS, Morson B. Primary malignant lymphoid tumours of the intestinal tract. Report of 37 cases with a study of factors influencing prognosis. BMC Cancer. 2010;49(213):80-89.

42. Hernandez-Ilizaliturri FJ, George Deeb MD, Zinzani PL, et al. Higher response to lenalidomide in relapsed/refractory diffuse large B-cell lymphoma in nongerminal center B-cell-like than in germinal center B-cell-like phenotype. Cancer. 2011;117(22):5058-5066. doi:10.1002/ cncr.26135

43. Izutsu K. Malignant lymphoma: pathophysiology and current therapy. Rinsho Ketsueki. 2017;58(5):480-486. doi:10.11406/rinketsu.58.480

44. Nishitha R, George D, Mark R, et al. Immunomodulatory drugs stimulate natural killer-cell function, alter cytokine production by dendritic cells, and inhibit angiogenesis enhancing the anti-tumour activity of rituximab in vivo. Br J Haematol. 2010;140(1):36-45.
45. Appel S, Balabanov S, Brummendorf TH, Brossart P. Effects of imatinib on normal hematopoiesis and immune activation. Stem Cells. 2005;23(8):1082-1088. doi:10.1634/stemcells.2005-0069

46. Dushyant V, Hagop K, Strom SS, et al. Malignancies occurring during therapy with tyrosine kinase inhibitors (TKIs) for chronic myeloid leukemia (CML) and other hematologic malignancies. Blood. 2011;118(16):4353-4358. doi:10.1182/blood-2011-06362889

47. Nakazato T, Iriyama N, Tokuhira M, et al. Incidence and outcome of second malignancies in patients with chronic myeloid leukemia during treatment with tyrosine kinase inhibitors. Med Oncol. 2018;35 (7):99. doi:10.1007/s12032-018-1159-7

48. Bohers E, Viailly PJ, Dubois S, et al. Somatic mutations of cellfree circulating DNA detected by next-generation sequencing reflect the genetic changes in both germinal center B-cell-like and activated B-cell-like diffuse large B-cell lymphomas at the time of diagnosis. Haematologica. 2015;100(7):280-284. doi:10. 3324/haematol.2015.123612

49. Scherer F, Kurtz DM, Newman AM, et al. Distinct biological subtypes and patterns of genome evolution in lymphoma revealed by circulating tumor DNA. Sci Transl Med. 2016;8(364):364ra155. doi:10.1126/scitranslmed.aaf0746

50. Rossi D, Diop F, Spaccarotella E, et al. Diffuse large B-cell lymphoma genotyping on the liquid biopsy. Blood. 2017;129(14):19471957. doi:10.1182/blood-2016-05-719641

51. Wu FT, Lu L, Xu W, Li J. Circulating tumor DNA: clinical roles in diffuse large B cell lymphoma. Ann Hematol. 2019;98(2):255-269. doi:10.1007/s00277-018-3529-9

52. Jr DL, Bardelli A. Liquid biopsies: genotyping circulating tumor DNA. J Clin Oncol. 2014;32(6):579-586. doi:10.1200/JCO. 2012.45.2011

53. Camus V, Jardin F, Tilly $H$. The value of liquid biopsy in diagnosis and monitoring of diffuse large b-cell lymphoma: recent developments and future potential. Expert Rev Mol Diagn. 2017;17(6):557566. doi:10.1080/14737159.2017.1319765
OncoTargets and Therapy

\section{Publish your work in this journal}

OncoTargets and Therapy is an international, peer-reviewed, open access journal focusing on the pathological basis of all cancers, potential targets for therapy and treatment protocols employed to improve the management of cancer patients. The journal also focuses on the impact of management programs and new therapeutic agents and protocols on patient perspectives such as quality of life, adherence and satisfaction. The manuscript management system is completely online and includes a very quick and fair peer-review system, which is all easy to use. Visit http://www.dovepress.com/ testimonials.php to read real quotes from published authors. 